\title{
ANALISIS KELAYAKAN USAHATANI KELINCI DI DESA UMBULREJO KECAMATAN UMBULSARI KABUPATEN JEMBER
}

\section{FEASIBILITY ANALYSIS OF USAINANI KELINCI IN VILLAGES of UMBULREJO, SUB DISTRICT UMBULSARI, District of JEMBER}

Atok Ainur Ridho dan Henik Prayuginingsih

Prodi Agribisnis, Faperta, Universitas Muhammadiyah Jember

Email : $\underline{\text { ridho_qu@yahoo.com }}$

\begin{abstract}
ABSTRAK
Kontinyuitas pemasaran hasil produksi yang tidak stabil akibat iklim serta keterbatasan modal menyulitkan peternak kelinci di desa Umbulrejo, Kecamatan Umbulsari, Kabupaten Jember. Tujuan penelitian adalah mengukur (1) keuntungan, (2) efisiensi biaya dan (3) rentabilitas. Penelitian menggunakan metode deskriptif-analitik dan survei. Daerah penelitian ini ditentukan secara sengaja dengan pertimbangan bahwa daerah tersebut mempunyai peternak yang potensial usahatani kelinci. Penelitian dilaksanakan sejak Oktober hingga Desember 2017. Obyek penelitian adalah peternak kelinci. Sampel penelitian ditentukan berdasar metode snow ball hingga tercapai kuota 18 orang. Metode analisis data yang digunakan adalah analisis keuntungan, effisiensi biaya dan rentabilitas. Hasil Penelitian adalah : (1) tingkat keuntungan peternak kelinci sistem kandang batere di desa Umbulrejo, Kecamatan Umbulsari, Kabupaten Jember sebesar Rp 2.245.050 per 10 ekor induk kelinci per tahun atau rata-rata per bulan $\mathrm{Rp} 187.088$, (2) penggunaan biaya usaha pembesaran gurami effisien ditunjukkan dengan nilai $\mathrm{R} / \mathrm{C}$ ratio sebesar 1,81. dan (3) Rentabilitas usaha sebesar 115,29 \%. Berdasarkan nilai tersebut maka usaha budidaya kelinci sistem batrai lebih menguntungkan daripada menyimpan uang di Bank dengan suku bunga bank yang diasumsikan sebesar $12 \%$ per tahun.
\end{abstract}

Kata Kunci: kelinci, keuntungan, effisiensi biaya, rentabilitas

\section{ABSTRACT}

The unstable continuity of product marketing due to climate and limited capital makes rabbit breeders in Umbulrejo village, Umbulsari sub-district, Jember regency was so difficult to develop. The objectives of the study were to measure (1) benefits, (2) cost efficiency and (3) rentability. The research used descriptive-analytic and survey methods. This area of research is determined deliberately with the consideration that the area has potential breeder rabbit farming. The study was conducted from October to December 2017. Research objects are rabbit breeders. The sample of research was determined by snow ball method until the quota was reached 18 people. Data analysis method was based on profit analysis, cost efficiency and rentability. The result of this research are: (1) profit level of rabbit breeder with battere cage system in Umbulrejo village, Umbulsari sub district, Jember regency is Rp 2,245,050 per 10 rabbit parent per year or average per month is $R p 187.088$, (2) the use of efficient gouramy enlargement cost is indicated by the $R / C$ ratio of 1.81 . and (3) investment rentability is $115.29 \%$. Based on that value, it can be concluded that battere system on rabbit farming is more profitable than saving money in the Bank with a bank rate assumed at $12 \%$ per year.

Keywords: rabbit, profit, cost efficient, rentability

\section{PENDAHULUAN}

Keberhasilan pembangunan suatu bangsa ditentukan oleh ketersediaan sumberdaya manusia (SDM) yang berkualitas, yaitu SDM yang memiliki fisik yang tangguh, mental yang kuat, kesehatan yang prima, serta cerdas. Bukti empiris menunjukkan bahwa hal ini sangat ditentukan oleh status gizi yang baik, dan status gizi yang baik ditentukan oleh jumlah asupan pangan yang dikonsumsi. Apabila gizi kurang dan gizi buruk terus terjadi dapat menjadi faktor penghambat dalam 
pembangunan nasional. Beberapa dampak buruk kurang gizi adalah: (i) rendahnya produktivitas kerja; (ii) kehilangan kesempatan sekolah; dan (iii) kehilangan sumberdaya karena biaya kesehatan yang tinggi (World Bank, 2006). Untuk menjaga agar individu tidak kekurangan gizi maka akses setiap individu terhadap pangan harus dijamin. Akses pangan setiap individu ini sangat tergantung pada ketersediaan pangan dan kemampuan untuk mengaksesnya secara kontinyu. Kemampuan mengakses pangan ini dipengaruhi oleh daya beli, yang berkaitan dengan tingkat pendapatan dan kemiskinan seseorang.

Dalam rangka mencapai solusi masalah tersebut, sektor pertanian yang mencakup tanaman pangan, tanaman perkebunan, perikanan dan peternakan akan terus dikembangkan menjadi pertanian yang maju, efisien dan tangguh. Sektor peternakan merupakan salah satu sektor yang mampu menjadikan solusi terhadap permasalahan untuk meningkatkan daya beli masyarakat dengan usaha yang dilakukan sehingga pendapatan masyarakat meningkat dan terhindar dari kemiskinan. Salah satu usaha ternak yang bisa dibudidayakan masyarakat adalah adalah usahatani kelinci. Kelinci merupakan salah satu ternak yang mudah dibudidayakan dengan tingkat produktivitas anakan yang tinggi, pakan yang mudah didapatkan disekitar kita, serta banyaknya masyarakat yang menggemari sebagai hewan piaraan maupun masyarakat pecinta kuliner daging olahan kelinci.

Banyaknya tempat pariwisata dan pujasera di kota sekitar memberikan peluang kepada setiap pembudidaya untuk terus melakukan usaha budidaya kelinci. Namun, keterbatasan modal dan juga adanya ketidak stabilan pasar serta harga jual output produksi ditambah lagi minimnya pengetahuan pengolahan produk daging yang memiliki nilai tambah menyebabkan pembudidaya kesulitan melakukan pengusahaan kelinci. Oleh karena itu penulis merasa perlu melakukan analisis kelayakan usaha budidaya kelinci di Desa Umbulrejo, Kecamatan Umbulsari, Kabupaten Jember untuk menilai usaha yang dilakukan dengan tujuan untuk mengukur investasi usaha, besar keuntungan dan menganalisis kelayakan usaha dengan indikator rentabilitas.

\section{METODE PENELITIAN}

\section{Metode Penelitian}

Metode penelitian menggunakan metode deskriptif-analitik dan juga survei. Metode deskriptif digunakan untuk mendeskripsikan secara terinci suatu aktivitas usahatani. Sementara metode analitik digunakan untuk menguraikan berbagai fenomena dalam penelitian. Metode survei adalah adalah metode yang bertujuan untuk mengumpulkan informasi yang sejenis dari berbagai kelompok/orang (Nazir, 1985).

\section{Lokasi dan Waktu Penelitian}

Penelitian dilaksanakan di Desa Umbulrejo, Kecamatan Umbulsari, Kabupaten Jember, JawaTimur. Daerah penelitian ini ditentukan secara sengaja (Purposive Method) dengan pertimbangan bahwa daerah yang terkenal dengan sentra produksi jeruk tersebut juga mempunyai potensi untuk mengembangkan usahatani ternak kelinci.

Waktu penelitian lapang direncanakan selama 6 minggu pada bulan November dan Desember 2017.

\section{Metode Pengumpulan data}

Data yang digunakan terdiri dari data primer dan sekunder. Data primer dikumpulkan melalui tekhnik wawancara berdasarkan daftar pertanyaan yang telah disusun. Data sekunder dikumpulkan dari instansi yang berhubungan dengan penelitian ini. Instansi yang terkait dalam pengumpulan data sekunder dalam penelitian ini antara lain Dinas Pertanian Kabupaten Jember dan Badan Pusat Statistik (BPS) Kabupaten Jember.

\section{Metode Pengambilan Sampel}

Pengambilan sampel pada penelitian ini dilakukan pada peternak yang mengusahakan usahatani kelinci, sedangkan metode pengambilan sampel yang akan 
diambil menggunakan metode "sensus sampling" yaitu semua populasi akan dijadikan sebagai sampel. Metode tersebut dipakai mengingat jumlah peternak yang masih melakukan aktifitas budidaya kelinci di desa Umbulrejo kecamatan Umbulsari 18 peternak.

\section{Metode Analisis Data}

1. Untuk mengukur besarnya investasi budidaya kelinci dilakukan tabulasi data terhadap data yang terkumpul dari hasil wawancara dan pengamatan di lapang .

2. Untuk mengukur keuntungan digunakan pendekatan teori keuntungan dengan persamaan sebagai berikut:

$$
\pi=\mathrm{Y} \times \mathrm{P}_{\mathrm{Y}}-\text { Biaya }
$$

$$
=(\text { Produksi } \times \text { Harga })-
$$

Biaya

$$
=\text { ( Produksi x Harga) - ( }
$$

Biaya tetap + Biaya variabel)

3. Untuk mengukur efisensi penggunaan biaya produksi digunakan pendekatan analisis $\mathrm{R}-\mathrm{C}$ ratio dengan rumus sebagai berikut(Soekartawi, 2002) :

$\mathrm{R}-\mathrm{C}$ ratio $=\frac{T R}{T C}$

Keterangan :

$\mathrm{TR}=$ penerimaan total budidaya kelinci ( $\mathrm{Rp})$

TC = biaya total budidaya kelinci (Rp)

$\mathrm{i}=$ suku bunga bank yang berlaku

Kriteria :

$\mathrm{R} / \mathrm{C}$ ratio > $1+\mathrm{i}$, berarti usahatani kelinci efisien

$\mathrm{R} / \mathrm{C}$ ratio $\leq 1+\mathrm{i}$, berarti usahatani kelinci tidak efisien.

4. Untuk mengukur rentabilitas digunakan rumus berikut (Riyanto, 1990

$$
\mathrm{ROI}=\frac{\pi}{\text { investasi }} \times 100 \%
$$

5. Untuk membandingkan antara nilai R$\mathrm{C}$ ratio dan ROI dengan suku bunga bank yang berlaku digunakan uji-t satu beda. Hipotesis yang diajukan adalah :
Ho : tidak ada perbedaan rata-rata nilai yang dibandingkan dengan suku bunga bank yang berlaku, atau $\mu=i$

$\mathrm{Ha}$ : ada perbedaan rata-rata nilai yang dibandingkan dengan suku bunga bank yang berlaku, atau $\mu \neq i$

\section{HASIL DAN PEMBAHASAN}

Kelinci adalah mamalia yang mudah dipelihara dan cepat berkembang biak (Sarwono, 2002). Kelinci berdasarkan tujuan produksinya dapat dibedakan menjadi : (1) kelinci sebagai penghasil bulu seperti angora dan rek, (2) kelinci pedaging seperti New Zealand White dan (3) kelinci yang dipakai untuk meningkatkan mutu kelinci lokal melalui kawin silang seperti d'argent, chinchilia, dutch, flemis giant, palamino dan satin (McNitt et al.,1996). Kelinci lokal yang kita kenal di Indonesia adalah kelinci yang asal usulnya tidak diketahui karena keturunan dari berbagai ras yang didatangkan ke Indonesia (Subroto, 2010).

Kelinci menjadi pilihan untuk dibudidayakan karena pakannya tidak bersaing dengan kebutuhan manusia, pemberian hijauan yang tinggi pada ternak kelinci dapat meningkatkan efisiensi pakan (Farrel dan Raharjo, 1984). Sartika et al. (1988) dan Sitorus et al. (1982), menyatakan bahwa beternak kelinci dapat memanfaatkan limbah pertanian maupun berbagai jenis hijauan sehingga dalam budidaya kelinci dapat menggunakan sumber daya lokal.

\section{Profil Responden Peternak}

Usaha budidaya kelinci dapat dilakukan dengan berbagai cara, ada yang dilakukan dengan sistem Postal (tanpa halaman pengumbaran), kandang sistem Ranch yang dilengkapi dengan halaman pengumbaran, ada juga sistem kandang Battery yaitu sangkar berderet dimana satu sangkar untuk satu ekor dengan konstruksi Flatdech Battery (berjajar), Tier Battery 
(bertingkat), Pyramidal Battery (susun piramid). Dalam setiap sistem kandang memiliki keistimewaaan serta kekurangan masing-masing, baik dari segi biaya maupun teknis. Kandang yang dilakukan peternak kelinci di Desa Umbulrejo, Kecamatan Umbulsari, Kabupaten Jember adalah kandang sistem Battery sebab tidak membutuhkan tempat yang luas dan dibuat bersusun bertingkat hal ini disebabkan usahatani yang dilakukan peternak kelinci di Desa Umbulrejo hanya sebagai penambah pendapatan bukan sebagai pendapatan utama.

Tabel 1 Profil Peternak Kelinci Sistem Kandang Battery di Desa Umbulrejo Kecamatan Umbulsari Kabupaten Jember 2017

\begin{tabular}{clcccc}
\hline \multirow{2}{*}{ No } & \multirow{2}{*}{ Profil } & \multirow{2}{*}{ Satuan } & \multicolumn{3}{c}{ Nilai } \\
\cline { 4 - 6 } & & Tahun & Rerata & Terrendah & Tertinggi \\
\hline 1 & Umur & Tahun & 11 & 29 & 56 \\
2 & Pendidikan & Tahun & 2,9 & 2 & 12 \\
3 & Pengalaman & Ekor & 26 & 15 & 4 \\
4 & Jumlah Indukan & ekor/kandang & 1 & 1 & 40 \\
5 & Kandang & & & & 1 \\
\hline
\end{tabular}

Sumber: Data primer diolah (2017).

Usaha budidaya kelinci bukanlah sesuatu yang sulit bagi peternak Desa Umbulrejo, beberapa jenis kelinci yang pernah dipelihara peterak adalah jenis Rex (karpet), lokal Unggul (silangan), Anggora, Lop, Flamish Giant. Diantara jenis diatas yang biasa dipelihara peternak adalah jenis Karpet dan Lokal Unggul dan Anggora, pilihan jenis kelinci yang dibudidayakan disesuaikan dengan kondisi permintaan/pasar serta jumlah anakan yang banyak serta dari sisi perawatan. Budidaya kelinci relatif masih baru di budidayakan, rata-rata peternak memelihara kelinci 2.9 tahun (Tabel 1).

Rerata umur peternak adalah 43,6 tahun, dengan peternak tertua berusia 56 tahun dan usia termuda 29 tahun. Kondisi ini menunjukkan bahwa ada generasi muda yang tertarik berwirausaha di bidang pertanian, peternakan khususnya, untuk peremajaan. Diharapkan jika banyak anak muda yang terlibat di bidang pertanian maka masa depan pertanian di Indonesia akan lebih baik, karena anak muda biasanya lebih berani, suka mencoba bahkan menemukan inovasi teknologi baru untuk perbaikan usaha. Sehingga ketahanan pangan serta peningkatan pendapatan konsumsi rumah tangga akan naik, pengangguran teratasi serta kondisi merantau kekota mencari pekerjaan dapat diminimalisir
Rerata pendidikan peternak tergolong baik, yaitu 11 tahun, terendah 6 tahun dan hanya satu orang jumlahnya serta tertinggi 17 tahun. Ini berarti tidak ada peternak yang tidak bisa membaca karena sudah lulus SD dan rata-rata peternak kelinci berpendidikan SMA, SPPMA, SMK. Pendidikan penting untuk keluasan wawasan dan kemudahan menerima dan menerapkan teknologi baru untuk perbaikan usaha.

Luas kandang dan jumlah Indukan yang diusahakan bergantung pada kemampuan finansial peternak karena berhubungan dengan biaya pembelian Induk serta pembuatan kandang. Ratio antara Indukan kelinci dengan luas kandang menunjukkan kesesuaian dengan referensi yang ada. Menurut anjuran, kandang Indukan Kelinci per ekor dengan luasan kandang $60 \times 70 \times 45 \mathrm{~m}^{2}$ dan peternak Kelinci di Desa Umbulrejo per ekor Indukan dengan luasan Kandang 60 x 70 x 50. Hasil analisis lapang menunjukkan angka yang sesuai anjuran literatur hal ini menunjukkan pemahaman para peternak terhadap kelinci yang dibudidayakan terkait dengan kesesuaian kandang akan menciptakan kenyamanan ternak yang berpengaruh positif terhadap kesehatan dan hasil anakan yang akan didapatkan. 


\section{Struktur Biaya Usaha Kelinci}

Biaya yang dikeluarkan peternak kelinci sistem kandang Battery di Desa Umbulrejo dapat dibedakan atas biaya tetap dan biaya Tabel 2 Biaya Usahatani Kelinci Sistem Kandang Battery per 10 ekor Indukan di Desa Umbulrejo Kecamatan Umbulsari Kabupaten Jember 2017

\begin{tabular}{|c|c|c|c|}
\hline \multirow{2}{*}{$\frac{\text { No }}{1}$} & \multirow{2}{*}{$\frac{\text { Uraian }}{\text { Biaya Tetap }}$} & \multirow[t]{2}{*}{ Nilai (Rp) } & Prosentase $(\%)$ \\
\hline & & & \\
\hline & - Penyusutan Kandang & $111.398,19$ & 3,88 \\
\hline 2 & Biaya Variabel & & \\
\hline & a. Pakan & $1.681 .285,37$ & 58,61 \\
\hline & b. Tenaga Kerja & $849.208,04$ & 29,60 \\
\hline & c. Obat obatan + Lain-lain & $19.092,65$ & 0,66 \\
\hline & d. Penyusutan Indukan & $207.777,66$ & 7,24 \\
\hline & Jumlah B. Variabel & 2.757.363,72 & 96,11 \\
\hline 3 & Biaya Total & 2.868.761,91 & 100,00 \\
\hline
\end{tabular}

Sumber: Data primer diolah (2017).

Biaya terbesar usahatani kelinci sistem Battery $(88,87 \%)$ di Desa Umbulrejo adalah biaya variabel, 58,61 \% diantaranya digunakan untuk biaya pakan kelinci. Peternak selama proses produksi, kelinci diberi pakan dua kali sehari pada pagi dan sore dengan pakan ampas tahu, sentrat dan rumput hijau. Keuntungan budidaya kelinci dengan sistem kandang battery ini sangat efektif karena tidak banyak memakan tempat dan dibuat tersusun bertingkat. Biaya variabel terbesar kedua adalah untuk tenaga kerja $(29,60 \%)$. Tenaga kerja dilakukan oleh peternak sendiri secara otomatis peternak mendapatkan tambahan penghasilan yang dapat meningkatkan penghasilan dari usaha yang dilakukan.

Biaya Indukan sebesar 7,24\%. Indukan yang dijadikan sebagai penghasil anakan budidaya kelinci yang dilakukan peternak di Desa Umbulrejo adalah indukan yang mulai produktif sampai usia indukan 3 tahun, sebab menurut informasi dari salah satu peternak saudara riky jika usia melebihi 3 tahun maka hasil anakan yang dihasilkan kurang maksimal sehingga kelinci yang sudah berusia 3 tahun menghasilkan anakan akan dijual sebagai kelinci pedaging dan indukan di remajakan dengan indukan yang muda. Biaya variabel yang selanjutnya yaitu biaya obat-obatan dan biaya lain-lain sebesar $(0,66 \%)$, hal ini menunjukkan variabel. Biaya tetap dikeluarkan untuk biaya sewa lahan, sedangkan biaya variabel terdiri dari biaya benih, pakan, tenaga kerja dan biaya lain-lain (Tabel 2). bahwa para peternak kelinci di Desa Umbulrejo dengan sistem kandang battery sudah memiliki kemampuan perawatan ternak yang mumpuni yang terlihat bahwa dengan biaya obat-obatan serta lainnya hanya sebesar $0,66 \%$.

Selain biaya variabel ada juga biaya tetap sebesar $(3.88 \%)$, biaya tetap ini merupakan biaya pembuatan kandang kelinci sistem battery. Peternak di Desa Umbulrejo menggunakan model kandang ini karena rata- rata para peternak dalam melakukan usahanya merasa lebih mudah dalam pengelolaan ternaknya, mengingat para peternak rata-rata pekerja di pabrik dan juga sebagian dari mereka yang bertani.

\section{Analisis Keuntungan, Effisiensi Biaya dan Rentabilitas Usahatani Kelinci}

Keuntungan, effisiensi biaya dan rentabilitas merupakan beberapa diantara banyak indikator untuk mengukur kelayakan usaha. Keuntungan merupakan selisih antara penerimaan (hasil penjualan) dengan biaya total. Effisiensi biaya dapat diketahui dari ratio biaya dan penerimaan. Sedangkan rentabilitas merupakan ratio keuntungan yang investasi yang digunkan untuk menghasilkna keuntungan tersebut. Dalam kasus usaha budidaya kelinci sistem kandang battery, investasi yang diperlukan sebesar biaya dalam periode satu tahun, 
sehingga rentabilitas usaha budidaya kelinci sistem kandang battery merupakan ratio keuntungan dan biaya. Tabel 3 berikut memberikan gambaran tentang ketiga indikator kelayakan usaha tersebut.

\section{Keuntungan Usaha Budidaya Kelinci Sistem Kandang Battery}

Berdasar Tabel 3 nampak bahwa usaha budidaya kelinci sistem kandang battery di lokasi penelitian secara rata-rata mampu menghasilkan keuntungan sebesar Rp 2.245.050,- per 10 ekor indukan/tahun dengan umur panen anakan rata-rata usia 2530 hari setelah lahir atau rata-rata per bulan Rp 187.087,-. Keuntungan ini relatif kecil, namun jika peternak memiliki jumlah kelinci yang lebih banyak maka keuntungan yang diperoleh juga akan semakin besar. Peternak biasanya mempunyai beberapa petak kandang yang kosong sebagai antisipasi musim panen jika over produksi karena keterlambatan tengkulak mengambil anakan akibat faktor cuaca atau sepinya permintaan, maka kelinci anakan ditaruh pada kandang yang kosong sehingga masa perkawinan indukan kelinci tidak terganggu dan bisa dilakukan sedemikian rupa sehingga peternak bisa mengatur masa panen periode berikutnya. Pengaturan masa kawin, bertujuan untuk Peternak bisa mengatur perkawinan kelinci sehingga peternak bisa menentukan kapan hasil anakan bisa dijual. Peternak kelinci di Desa Umbulrejo melakukan usahanya sebagai pekerjaan sampingan dengan memanfaatkan sisa waktu yang dimiliki oleh peternak, selebihnya digunakan untuk pekerjaan utamanya untuk memperoleh pendapatan guna memenuhi kebutuhan keluarga.

Tabel 3 Rata-rata Keuntungan, Effisiensi Biaya dan Rentabilitas Usaha Biaya Usahatani Kelinci Sistem Kandang Battery per 10 ekor Indukan di Desa Umbulrejo Kecamatan Umbulsari Kabupaten Jember 2017

\begin{tabular}{crcccc}
\hline \multirow{2}{*}{ No. } & \multirow{2}{*}{ Uraian } & \multirow{2}{*}{ Satuan } & \multicolumn{3}{c}{ Nilai } \\
\cline { 4 - 6 } & & Rerata & Terendah & Tertinggi \\
\hline 1. & Produksi & Anakan & 267,77 & 200 & 313 \\
2. & Harga & Rp/ekor & 19.133 & 15.000 & 30.000 \\
3. & Penerimaan & Rp & 5.113 .811 & 3.600 .000 & 8.100 .000 \\
4. & Biaya & Rp & 2.868 .762 & 1.862 .500 & 3.396 .667 \\
5. & Keuntungan & Rp/tahun & 2.245 .050 & 626.667 & 5.002 .084 \\
& & Rp/bulan & 187.087 & 52.222 & 416.840 \\
6. & R/C-ratio & - & 1,81 & 1,211 & 2,615 \\
7. & Rentabilitas & $\%$ & 115,29 & 36,15 & 300,13 \\
\hline
\end{tabular}

Sumber: Data primer diolah (2017).

Dari 18 responden penelitian ada satu responden yang mengalami keuntungan yang berbeda, dengan harga yang lebih tinggi dari pada peternak yang lainnya. Berdasar data lapang hal ini bisa terjadi lantaran peternak tersebut menjual sendiri ternaknya secara langsung di pasaran sehingga peternak tersebut mendapatkan rentang selisih pendapatan dibandingkan dengan peternak yang lainnya, namun walaupun peternak tersebut mendapatkan hasil jual yang tinggi dibanding dengan peternak yang lainnya yang merpengaruh terhadap pendapatannya, akan tetapi peternak tersebut harus mengeluarkan biaya yang lebih berkaitan dengan biaya transportasi lokasi yang dituju untuk berjualan serta tenaganya untuk berjualan.

\section{Effisiensi Biaya Usaha Budidaya Kelinci Sistem Kandang Battery}

Hasil analisis menunjukkan bahwa rata-rata $\mathrm{R} / \mathrm{C}$ ratio usaha budidaya kelinci sistem kandang Battery kelinci pe 10 indukan sebesar 1,81. Nilai $\mathrm{R} / \mathrm{C}$ ratio ini berarti bahwa setiap rupiah biaya yang dikeluarkan menghasilkan penerumaan sebesar Rp 1,81 atau setiap pengeluaran biaya sebesar Rp 1.000,- dapat menghasilkan penerimaan sebesar Rp 1.810. Hal ini menunjukkan bahwa usaha ternak 
anakan kelinci effisien dalam penggunaan biaya. Apabila dibandingkan dengan suku bunga bank yang berlaku (12\% per tahun) maka usaha ini masih lebih menguntungkan karena menghasilkan penerimaan yang lebih besar dibanding menyimpan biaya di bank sebagai tabungan. Berdasar Tabel 4 terlihat bahwa terdapat beda nyata pada taraf kepercayaan $99 \%$ yang menunjukkan bahwa $\mathrm{R} / \mathrm{C}$ ratio usaha ternak anakan kelinci secara nyata lebih tinggi dibanding suku bunga bank.

Tabel 4. Hasil Analisis Uji Beda Rata-rata R/C-ratio dengan Suku Bunga Bank/tahun

Tet Value $=1.12$

$95 \%$ Confidence Interval of the Difference

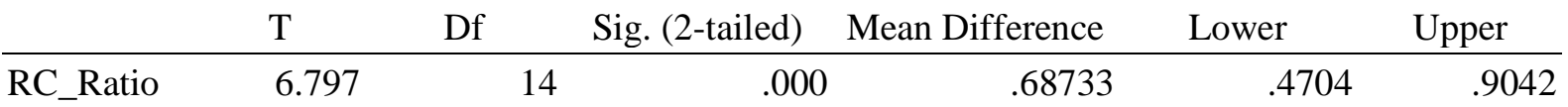

Sumber: Data primer diolah (2018)

\section{Rentabilitas Usaha Budidaya Kelinci Sistem Kandang Battery}

Rentabilitas adalah ratio antara keuntungan yang diperoleh dari investasi yang telah ditanamkan. Hasil analisis uji beda rata-rata rentabilitas dengan suku bunga/tahun menunjukkan bahwa rata-rata rentabilitas usaha budidaya kelinci sistem kandang battery per 10 indukan sebesar $115,29 \%$. Nilai rentabilitas sebesar 115,29 $\%$ berarti bahwa investasi yang telah ditanamkan di awal usaha budidaya kelinci sistem kandang battery dapat memberikan Tabel 5 Hasil Analisis Uji Beda Rata-rata Rentabilitas dengan Suku Bunga Bank/tahun keuntungan sebesar $115,29 \%$. Apabila dibandingkan dengan suku bunga bank yang berlaku (12\% per tahun) maka usaha budidaya kelinci sistem kandang battery ini masih lebih menguntungkan karena menghasilkan keuntungan yang lebih besar dibanding menyimpan investasi di bank sebagai tabungan. Berdasar Tabel 5 terlihat bahwa terdapat beda nyata pada taraf kepercayaan $99 \%$ yang menunjukkan bahwa rentabilitas usaha budidaya kelinci sistem kandang battery secara nyata lebih tinggi dibanding suku bunga bank.

Test Value $=12$

95\% Confidence Interval of the Difference

\begin{tabular}{llllllr} 
& T & Df & Sig. (2-tailed) & Mean Difference & Lower & Upper \\
Rentabilitas & 6.557 & 14 & .000 & 103.29067 & 69.5041 & 137.0772 \\
\hline
\end{tabular}

Sumber: Data primer diolah (2018)

\section{DAFTAR PUSTAKA}

Akhmad. 2014. Ekonomi Mikro Teori dan Aplikasi di Dunia Usaha CV Andi Offset. Yogyakarta.

Boediono. 1982. Pengantar Ilmu Ekonomi, Ekonomi Mikro. BPFE.

Yogyakarta.
Kementrian pertanian, 2015. Rencana strategis kementrian pertanian tahun 2015-2019

Nazir, M, 1985. Metode Penelitian, Ghalia Indonesi. Jakarta.

Pasaribu, Ali Musa. 2012. Perencanaan dan Evaluasi Proyek Agribisnis. Yogyakarta 
Pasek, I Wayan. 2005. Teknis Berternak Kalinci. Balai Penelitian Ternak Ciawi. Bogor

Rahardi dan Rudi. 2004. Agribisnis Peternakan. Cetakan 9. Jakarta: Penebar Swadaya.

Raharjo, Y. C. 2012. Agribisnis Kelinci Skala Mikro, Kecil dan Menengah dalam Integrasi dengan Hortikultura untuk Penanggulangan Gizi Buruk/Ketahanan Pangan, Tambahan Pendapatan dan Pemberdayaan Tenaga Kerja. Balai Penelitian Ternak, Ciawi - Bogor.

Riyanto, B. $1990 . \quad$ Dasar-Dasar Pembelanjaan Perusahaan. Edisi 3. Yayasan Badan Penerbit Gadjah Mada. Yogyakarta.

Soekartawi. 2002. Teori Ekonomi Produksi, Dengan Pokok Bahasan Analisis Fungsi Cobb-Douglas, PT. Raja Grafindo Persada. Jakarta .

Sarwono, B. 2009. Kelinci Potong dan Hias. PT Agromedia Pustaka. Cetakan kedua belas Revisi. Jakarta
Sajimin, Y. C., Raharjo, N. D., Purwantari $\&$ Lugio. (2005). Produksi tanaman pakan ternak Stylosantethes hamata yang diberi pupuk kelinci. Seminar Nasional Teknologi Peternakan dan Veteriner. Departemen Pertanian. Badan Penelitian dan Pengembangan Pertanian .Puasat Penelitian dan Pengembangan Peternakan. Bogor.

Soekartawi. 2002. Teori Ekonomi Produksi, Dengan Pokok Bahasan Analisis Fungsi Cobb-Douglas, PT. Raja Grafindo Persada. Jakarta.

Soekartawi. 1995. Analisis Usaha Tani. UIPress. Jakarta.

Samuelson, P A. and Nordhaus, W.D. 1994. Ekonomi. Edisis ke duabelas. Alih Bahasa: A.Q. Khalid. Gelora Aksara Pratama. Jakarta

Syamsu, B. dan Bachtar, B. 2015. Pemanfaatan Limbah Sayuran Pasar untuk Pakan Kelinci dan Teknik Pengembangbiakannya serta Pengolahan Urin/Feses Kelinci Sebagai Pupuk Organik di DKI Jakarta Balai Pengkajian Teknologi Pertanian Jakarta

Yunus, A. 2010. Sukses Beternak Kelinci Potong. PB Pustaka Baru Pres 